\title{
AVALIAÇÃo DA COBERTURA FLORESTAL NO MUNICÍPIO DE MARINGÁ, PARANÁ
}

\author{
André Cesar Furlaneto Sampaio ${ }^{1}$; Christopher Thomas Blum² ${ }^{2}$ Paulo José Moraes Monteiro e Teixeira Germano ${ }^{3}$; \\ Bruno Luiz Domingos De Angelis ${ }^{4}$
}

\section{RESUMO}

O Estado do Paraná sofreu grande degradação de suas florestas, sendo a Floresta Estacional Semidecidual a mais afetada. Essa degradação ocasionou uma fragmentação florestal que ocasiona prejuízos para a biodiversidade e o equilíbrio ambiental. O presente estudo teve como objetivo quantificar as áreas florestais existentes no município de Maringá entre 1990 e 2008. Para tal, foram selecionadas as imagens de satélite Landsat 5 mais adequadas para os referidos anos, as quais foram preparadas através de georreferenciamento e recortes para posterior classificação supervisionada. Foram estabelecidas três classes de cobertura do solo, com amostras de treinamento processadas pelo método do paralelepípedo. Verificou-se um aumento da cobertura florestal no município (25,2\%), concentrado principalmente nas margens de rios, provavelmente devido a um maior cumprimento da legislação ambiental. O maior aumento ocorreu no setor rural sul de Maringá, que passou de 7,9\% para 13,6\% de cobertura florestal entre 1990 e 2008.

Palavras-chave: Fragmentação florestal, Sensoriamento remoto, Floresta estacional semidecidual.

EVALUATION OF THE FOREST COVER IN THE MUNICIPALITY OF MARINGA, PARANA

\section{ABSTRACT}

The State of Parana has suffered severe degradation of its forests, and the Semidecidual Seasonal Forest has been the most affected forest type. This degradation resulted in a forest fragmentation with damages to biodiversity and environmental balance. This study aimed to quantify forest areas in the Maringa municipality between 1990 and 2008. For that, there were selected the more adequate Landsat 5 satellite images for the referred years, and they were prepared through georeferencing and segmentation for a supervised classification. There were established three classes of soil cover, whose training samples were processed by the parallelepiped method. It was verified an increase in forest cover in the county (25.2\%), especially concentrated along the rivers, probably due to the requirements of environmental legislation. The greater increase occurs in the south rural sector of Maringa, were the forest cover increased from 7,9\% to 13,6\% between 1990 and 2008.

Keywords: Forest fragmentation; Remote sensing; Semidecidual seasonal forest.

\footnotetext{
${ }^{1}$ Engenheiro Florestal, Doutorando em Geografia - Universidade Estadual de Maringá-PR -sampaio.floresta@gmail.com

2.Engenheiro Florestal, Doutor em Engenharia Florestal, UFPR, Curitiba, PR - blumct@gmail.com

${ }^{3 .}$ Geógrafo, Mestrando em Geografia, Universidade Estadual de Maringá-PR, Maringá, PR - geografia@ceppa.com.br

4.Agrônomo; Prof. do Departamento de Agronomia, Universidade Estadual de Maringá (UEM), Maringá, PR - brucagen@uol.com.br

${ }^{5}$ (recebido em 15.03.2011 e aceito para publicação em 15.06.2012)
} 


\section{INTRODUÇÃO}

O bioma Mata Atlântica, no qual se inserem vários ecossistemas florestais, apresenta altos índices de biodiversidade e de endemismo, mas encontra-se em situação crítica de alteração de seus ambientes, já que seus domínios hoje abrigam 70\% da população brasileira, além das maiores cidades e os mais importantes pólos industriais do Brasil. De acordo com dados recentes do Atlas dos Remanescentes Florestais da Mata Atlântica, o bioma está reduzido a apenas $7,3 \%$ do que existia originalmente (SOS MATA ATLÂNTICA; INPE, 2009).

No Paraná, a área de abrangência do bioma Mata Atlântica engloba 98\% do território do Estado e se constitui de distintas unidades fitogeográficas (ecossistemas florestais): Floresta Ombrófila Densa (Floresta Atlântica), Floresta Ombrófila Mista (Floresta com Araucária) e Floresta Estacional Semidecidual (Floresta Seca do Rio Paraná), além das formações nãoflorestais de Estepes e Savanas (Campos gerais e Cerrados) (RODERJAN et al., 2002). Originalmente a cobertura predominantemente era florestal, ocupando aproximadamente $84 \%$ da área do Estado, sendo o restante ocupado pelas formações campestres. Infelizmente, algumas décadas de exploração intensa e contínua foram suficientes para modificar esta paisagem. O processo de devastação, ocasionado pela ocupação antrópica, acabou por reduzir a cobertura florestal nativa do Estado para apenas 10,5\% do que havia originalmente, considerando o período de análise de 2005 até 2008 (SOS MATA ATLÂNTICA; INPE, 2009). Todos os ecossistemas florestais encontrados no Paraná foram degradados, restando porções significativamente inferiores às originais (WILLIS, 1979; BIERREGAARD; LOVEJOY, 1988; DURIGAN et al., 2000; CASTELLA; BRITEZ, 2004; FUNDAÇÃO SOS MATA ATLÂNTICA; INPE, 2009).

A Floresta Estacional Semidecidual (FES) foi o ecossistema florestal cuja devastação ocorreu de forma mais rápida e ampla no Paraná e em toda a sua área de ocorrência natural, que compreende parte dos Estados de
São Paulo, Minas Gerais, Santa Catarina, Rio Grande do Sul, Goiás, Mato Grosso do Sul, Bahia e Espírito Santo e de países vizinhos, como o Paraguai e a Argentina. A expansão da atividade agrícola iniciada no Norte do Paraná a partir de 1920, em função da boa fertilidade do solo, trouxe associada a ela a devastação da FES, que foi rapidamente reduzida a pequenos e esparsos fragmentos florestais. Dos fragmentos remanescentes, poucos têm área representativa e encontram-se preservados. Um dos principais problemas ocasionados por esta fragmentação intensa é a extinção de espécies que tem sido frequentemente documentada no Brasil e no mundo (WILLIS, 1979; BIERREGAARD; LOVEJOY, 1988; DURIGAN et al., 2000).

Maringá foi um dos municípios que teve sua área florestal mais devastada, estando atualmente entre aqueles com menor área de florestas nativas do Estado, com apenas 3\% de remanescentes no estágio avançado da sucessão (FUNDAÇÃO SOS MATA ATLÂNTICA; INPE, 2009).

Estudos sobre a situação das florestas que restaram são importantes para visualizar a gravidade desse problema ambiental e de como traçar diretrizes políticas e projetos para mitigar, compensar e recuperar esses danos ambientais.

Objetiva-se quantificar a cobertura florestal (remanescentes nativos em distintos estágios sucessionais e plantios florestais) no município de Maringá, Paraná, através do uso de imagens de satélite, registradas em 1990 e 2008 e, com isso, determinar o aumento ou redução desta área.

Dessa forma, este trabalho tem o intuito de colaborar no estudo da paisagem do Norte do Paraná, focando o município de Maringá. Os resultados irão colaborar para um entendimento maior do estado atual do processo de devastação e no direcionamento de ações e medidas para a melhora da qualidade ambiental na paisagem deste município. 


\section{MATERIAIS E MÉTODOS}

O Município de Maringá (Figura 1) possui uma área de 489,76 km2 e localiza-se na Região Sul do Brasil, na porção Noroeste do Estado do Paraná, mais precisamente

Figura 1. Mapa com a localização do Município de Maringá, Paraná

Figure 1. Map showing the location of the Maringa municipality, Parana
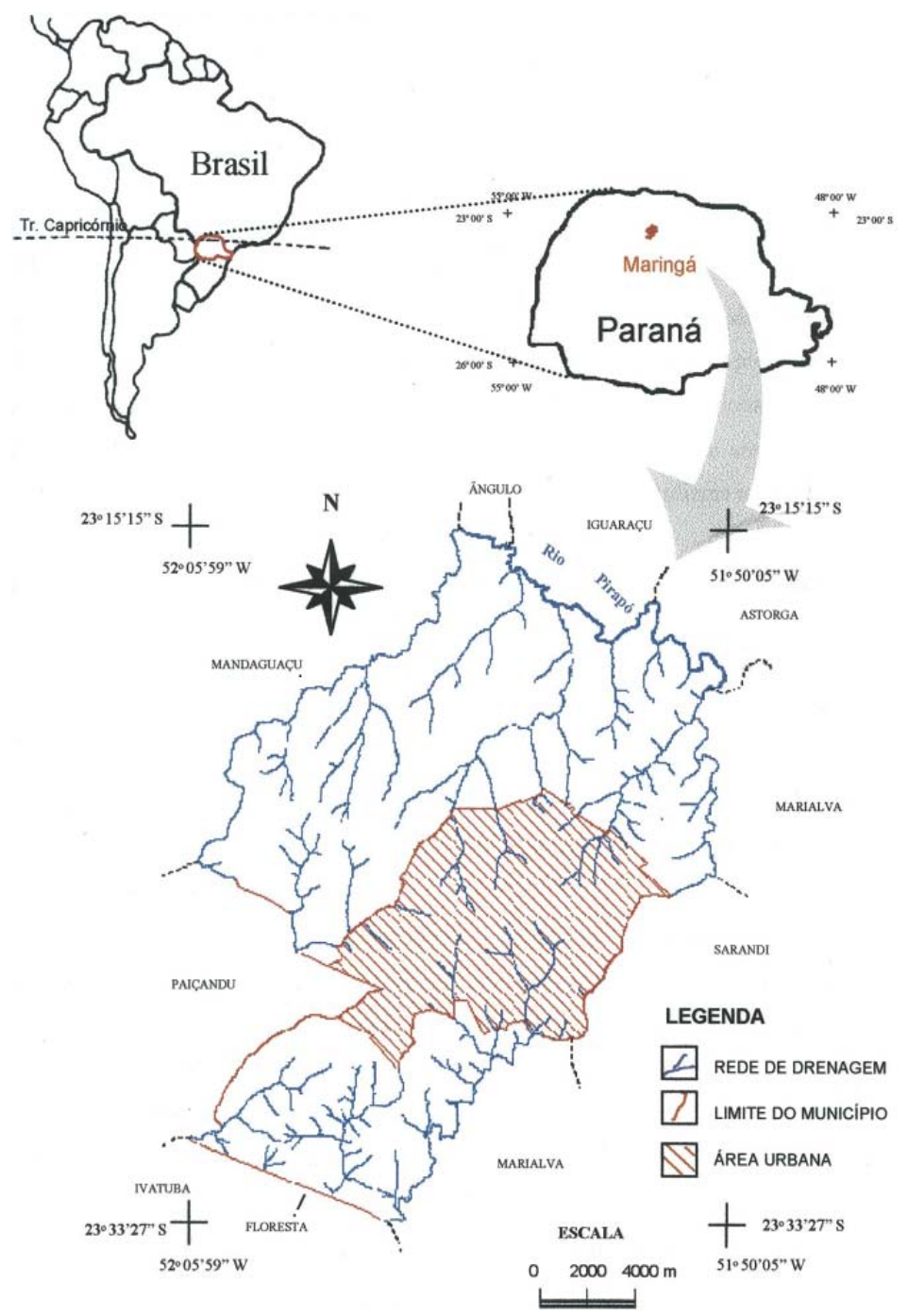

no terceiro Planalto, entre as coordenadas $23^{\circ} 25^{\prime} \mathrm{S}$ e 515’ W, sendo cortado ao sul pela linha imaginária do Trópico de Capricórnio (BARROS et al., 2004).

O clima no município de Maringá, segundo a classificação de Köppen, é do tipo subtropical Cfa, com verões quentes, geadas pouco frequentes e chuvas abundantes no verão. Geologicamente caracteriza-se pelos derrames basálticos da Formação Serra Geral, pertencente ao Grupo São Bento, capeados a oeste pelos arenitos da Formação Caiuá, Grupo Bauru (BARROS et al., 2004). O Município de Maringá possui relevo predominantemente suave ondulado, com altitudes variando entre 500 e 600 m (BARROS et al., 2004). De acordo com Paiva et al. (2009), cerca de $70 \%$ do município está entre as cotas altimétricas de 420 a $540 \mathrm{~m}$. Os solos mais comuns na região são Nitossolo, Latossolo Roxo, Latossolo Vermelho-Escuro e Neossolo Litólico (BARROS et al., 2004). De acordo com o delineamento de Maack (1968) e adotando o Sistema Fisionômico-Ecológico de Classificação da Vegetação Brasileira, proposto por Veloso e Góes-Filho (1982), o município de Maringá enquadra-se na região fitogeográfica da Floresta Estacional Semidecidual. 
Para se atingir os objetivos de verificação da cobertura florestal remanescente nas áreas urbana e rural de Maringá foram selecionadas duas imagens de satélite, fornecidas gratuitamente pelo Instituto Nacional de Pesquisas Espaciais (INPE). Para tal, foi realizada uma seleção das melhores imagens que recobriam a área de estudo nos anos predefinidos, sem interferência de nuvens, englobando todo o município de Maringá e com resolução mínima de 30 metros, critérios considerados suficientes para atingir os objetivos do estudo. As imagens utilizadas, abrangendo os anos de 1990 e 2008, foram:

- Imagem de Satélite Landsat 5, sensor TM, referente à órbita 222, ponto 76, bandas TM1, TM2, TM3, TM4 e TM5, de 06/08/1990; e

- imagem de Satélite Landsat 5, sensor TM, referente à órbita 222, ponto 76, bandas TM1, TM2, TM3, TM4 e TM5, de 24/09/2008.

As imagens foram trabalhadas no software ENVI 4.5 (software para visualização, exploração, análise e apresentação de dados na área de Sensoriamento Remoto/SIG). Inicialmente foi feito o georreferenciamento e recorte das imagens de satélite com a utilização de um vetor em formato dxf fornecido pela Prefeitura Municipal de Maringá, georreferenciado e com a definição dos limites das áreas rural e urbana. O método utilizado foi de associação de pontos de controle imagem e vetor.
Após esses trabalhos, cada imagem foi subdividida em três setores: área urbana central, área rural norte e área rural sul. Ressalta-se que nas áreas rurais existem distritos urbanos, que no presente trabalho foram considerados como parte integrante da área rural, por serem pequenos e pouco expressivos. A referida subdivisão facilitou o processo de definição do uso do solo, que focou os remanescentes florestais. Em cada recorte foi executada uma classificação supervisionada através do software ENVI 4.5.

A primeira fase de classificação foi o treinamento, durante o qual foram extraídas amostras de pixels, de mesmo tamanho, para cada recorte da imagem em três classes pré-definidas: 1) áreas desprovidas de floresta, 2) cobertura florestal, 3) corpos d'água. Na classe cobertura florestal foram incluídos remanescentes florestais nativos em diversos estágios sucessionais, além de povoamentos arbóreos com fins comerciais. Os dados de amostras das imagens foram processados pelo método do paralelepípedo, onde o software detectou pelos limiares das amostras se um pixel estava dentro ou fora das classes pré-estabelecidas. Com isso se obteve a quantificação dos remanescentes florestais de toda área do município em épocas diferentes, podendo-se assim fazer comparações e verificações da vegetação florestal restante nas zonas urbana e rural de Maringá.

\section{RESULTADOS E DISCUSSÃO}

Através do recorte do município de Maringá (Figura 2), pode-se observar a existência de uma área urbana bem consolidada na região central de seu território, separando as área rural nos setores norte e sul. 
Figura 2. Imagem Landsat 5, sensor TM, órbita 222, ponto 76, 24/09/2008, cores espectrais 3-2-1, georreferenciada e recortada nos limites do município de Maringá-PR

Figure 2. Landsat 5 Image, TM sensor, orbit 222, point 76, 24/09/2008, spectral colors 3-2-1, georeferenced and trimmed in the edge of Maringa-PR

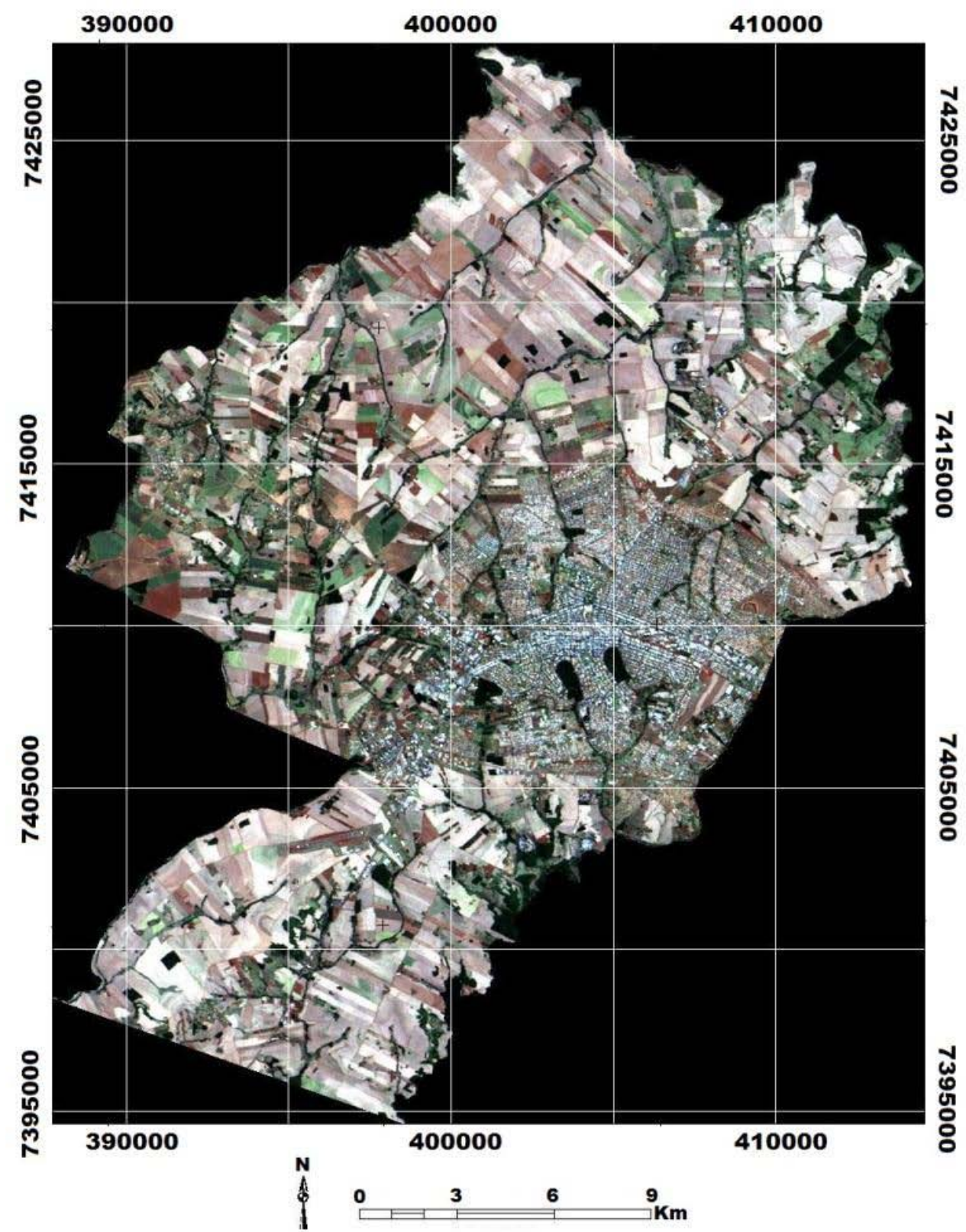

Fonte: INPE (2009)

Após o georreferenciamento e recorte dos limites do município, cada imagem foi recortada novamente retirando-se a área urbana central e subdividindo a área rural em dois setores (norte e sul) (Figuras 3 a 5). 
Figura 3. Recorte da área urbana do município de Maringá das imagens Landsat 5, sensor TM, órbita 222, ponto 76 , composição de cores bandas 3-2-1, nas respectivas datas 06/08/1990 (esquerda) e 24/09/2008 (direita)

Figure 3. Cut from the urban area of Maringá-PR from Landsat 5 images, TM sensor, orbit 222, point 76 , composition of color bands 3-2-1, on the respective dates 06/08/1990 (left) and 24/09 / 2008 (right)
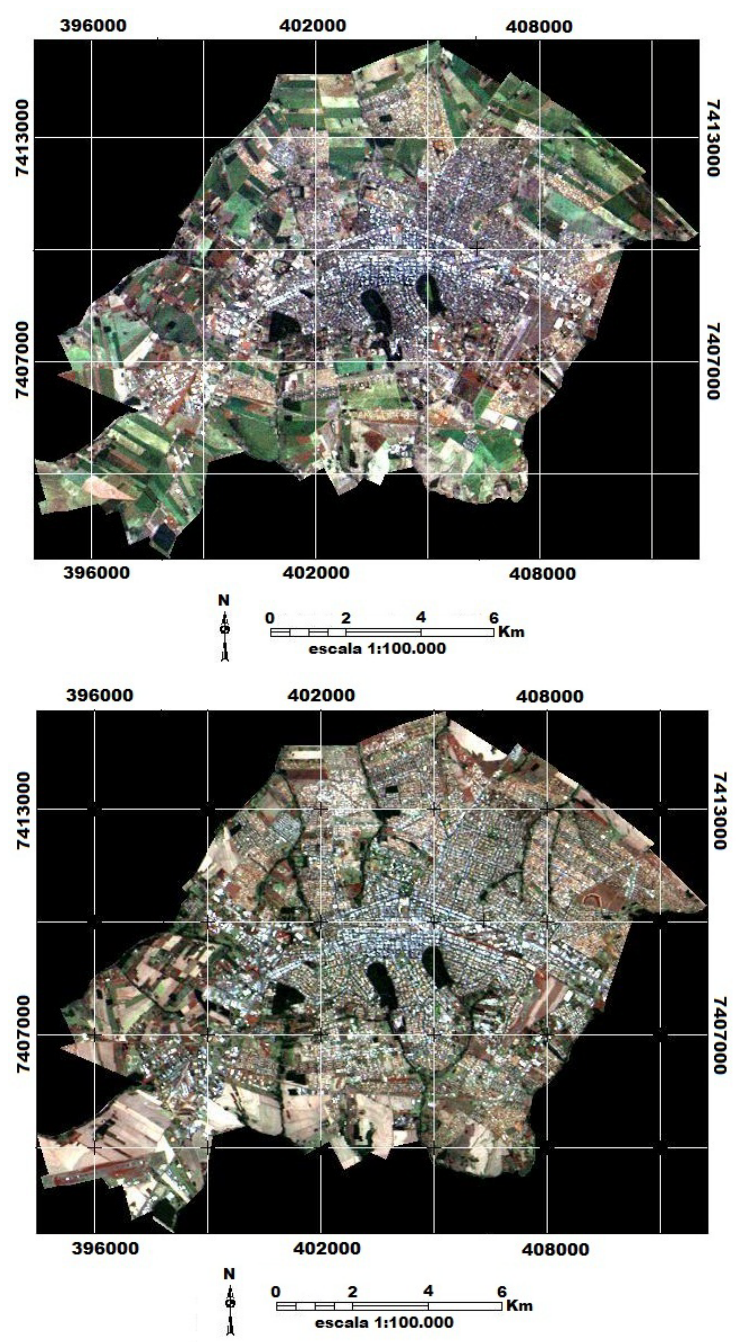

Fonte INPE 2009

Nas imagens da área urbana (Figura 3), antes de qualquer classificação, já é possível verificar visualmente que de 1990 até 2008 houve avanço da urbanização, desenvolvimento das florestas ripárias (Áreas de Preservação Permanente) e razoável acréscimo da arborização de vias públicas, deixando o verde entre as ruas mais intenso.
Nas imagens dos setores delimitados como da área rural (Figuras 4 e 5), é possível verificar que de 1990 até 2008 houve um avanço do desmatamento em determinados setores, porém, também ocorreu um desenvolvimento evidente de algumas florestas ripárias que, em 1990, se encontravam degradadas.

Figura 4. Recorte do setor rural norte do município de Maringá-PR (área rural norte) das imagens Landsat 5, sensor TM, órbita 222, ponto 76, composição de cores bandas 3-2-1, nas respectivas datas 06/08/1990 (esquerda) e 24/09/2008 (direita)

Figure 4. Cut from the northern rural sector of MaringaPR (rural area north) from Landsat 5 images, TM sensor, orbit 222, point 76, composition of color bands 3-2-1, on the respective dates 06/08/1990 (left) and 24/09/2008 (right)
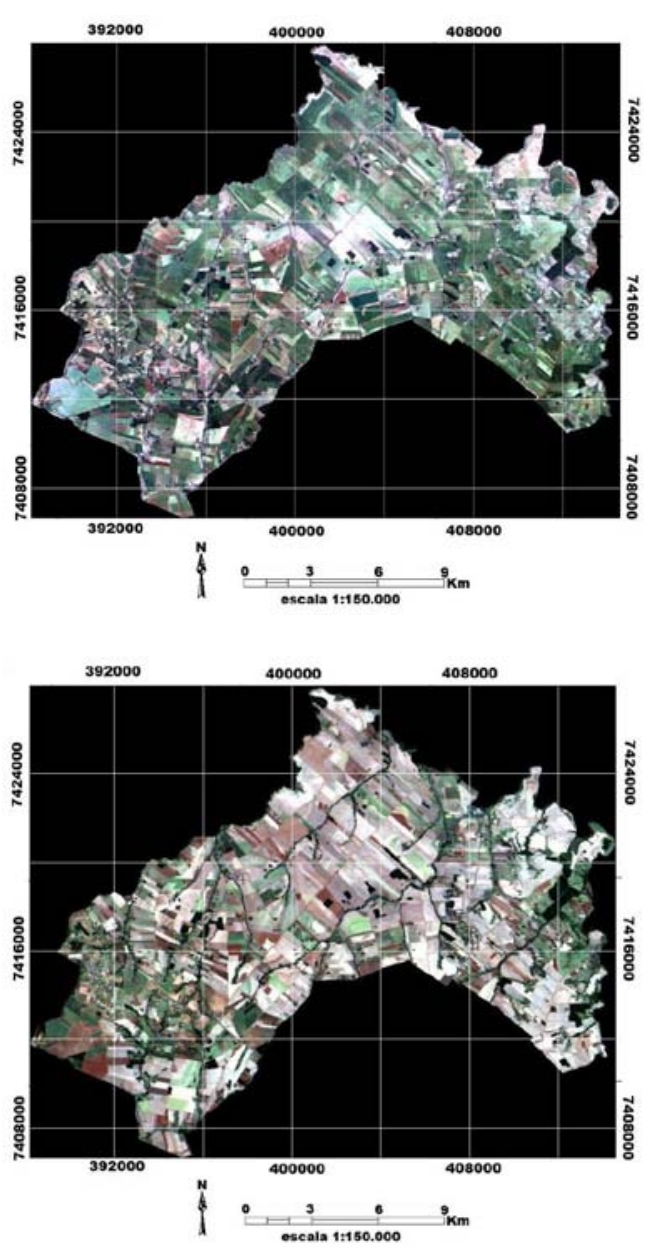

Fonte INPE 2009

André Cesar Furlaneto Sampaio... 
Figura 5. Recorte do setor rural sul do município de Maringá-PR (área rural sul) das imagens Landsat 5, sensor TM, órbita 222, ponto 76, composição de cores bandas 3-2-1, nas respectivas datas 06/08/1990 (esquerda) e 24/09/2008 (direita)

Figure 5. Cut from the southern rural sector of Maringa-PR (rural south) from Landsat 5 images, TM sensor, orbit 222, point 76, composition of color bands 3-2-1, on the respective dates 06/08/1990 (left) and 24/09/2008 (right)
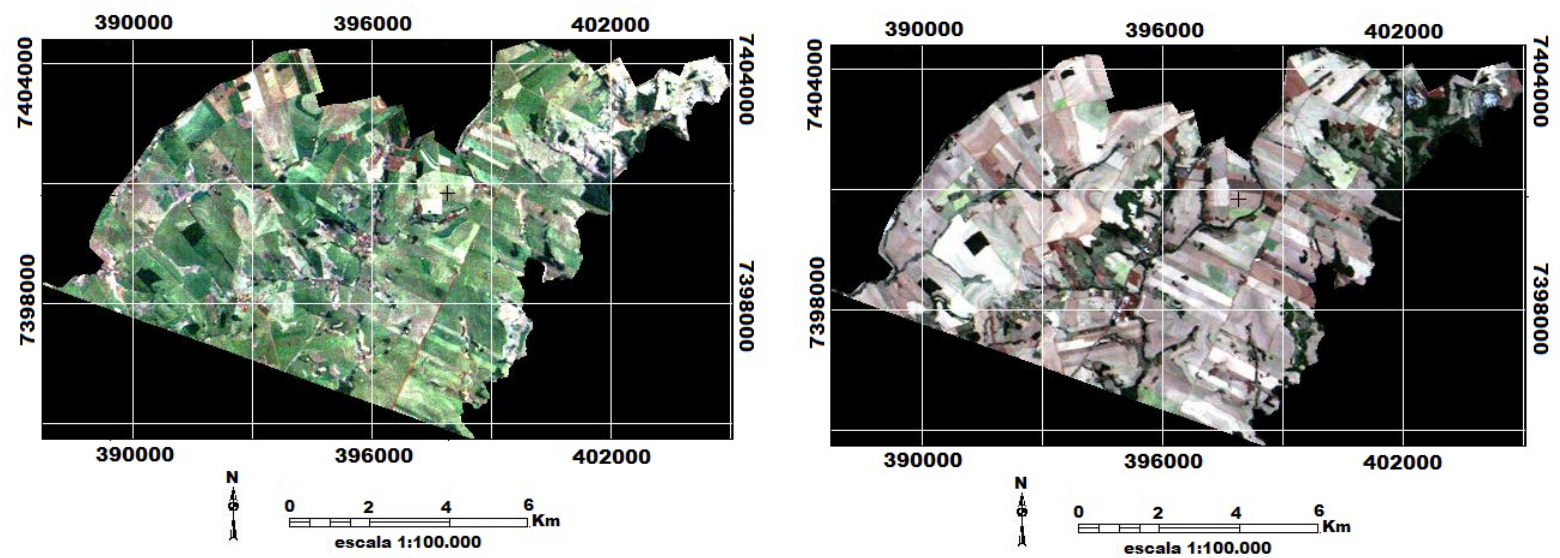

Fonte: INPE (2009)

Os resultados das classificações realizadas para cada recorte são representados nas Figuras 6 a 8 , que delineiam as tendências de redução ou aumento da cobertura florestal no período, para as zonas urbana e rural de Maringá.

Houve um aumento da cobertura florestal no setor da área urbana de 4,9\% (1990) para 8,2\% (2008), o que equivale a 2,47 km2 de acréscimo em áreas florestais, totalizando em 2008 11,15 km2. Ressalta-se que este montante total de cobertura florestal não inclui a cobertura arbórea das árvores de vias públicas (arborização urbana), pois os pixels destas tem pouca representatividade nas imagens de satélite com resolução de 30 metros.

De acordo com Sampaio (2008), em 2004, a arborização de vias públicas da cidade de Maringá totalizava uma cobertura arbórea de 8,05 km2. Considerando que a arborização de vias públicas tenha se mantido sem grandes alterações entre 2004 e 2008, o que é bastante provável, pode-se somar sua área de cobertura ao montante de áreas florestais obtido no presente trabalho, obtendo-se uma estimativa de cobertura arbórea total da área urbana de Maringá (parques, praças arborizadas, remanescentes florestais, florestas ripárias e arborização

das vias públicas) de 19,20 km2, o que equivale a 14,1\% de toda área urbana e aproximadamente 53,76m2/habitante, considerando uma população de 357.117 habitantes (IBGE, 2010).

Apesar de se tratar de um índice de cobertura arbórea consideravelmente expressivo, não se pode considerá-lo como um índice de áreas verdes em seu sentido convencional, uma vez que em geral o termo "área verde" se restringe aos espaços de vegetação urbana acessíveis para recreação da população, geralmente públicos (DEMATTÊ, 1997; NUCCI, 2001). Como ressaltado por Oliveira (1996), não existe até o momento uma padronização nacional para o cálculo do índice de áreas verdes, pois existem definições diferenciadas sobre o que deve constar como sendo área verde urbana, o que dificulta qualquer comparação entre municípios. Ainda assim, a título de referência, a Associação Nacional de Recreação dos Estados Unidos no Congresso Internacional de Recreação, realizado em 1956 na Filadélfia recomendou um índice de 28 a 40 m2 de área verde por habitante. Cavalheiro (1982) relatou que as cidades alemãs, em termos de cobertura verde total, deveriam atingir um índice médio de 33,5 m2 por 
habitante. Especificamente para áreas verdes públicas destinadas à recreação, a Sociedade Brasileira de
Arborização Urbana propôs como índice mínimo 15 m2/habitante (SBAU, 1996).

Figura 6. Classificação da área urbana do município de Maringá-PR das imagens Landsat 5, sensor TM, órbita 222, ponto 76, datas 06/08/1990 (acima) e 24/09/2008 (abaixo)

Figure 6. Classification of the urban area of Maringá-PR from Landsat 5 images, TM sensor, orbit 222, point 76, dates 06/08/1990 (above) and 24/09/2008 (below)
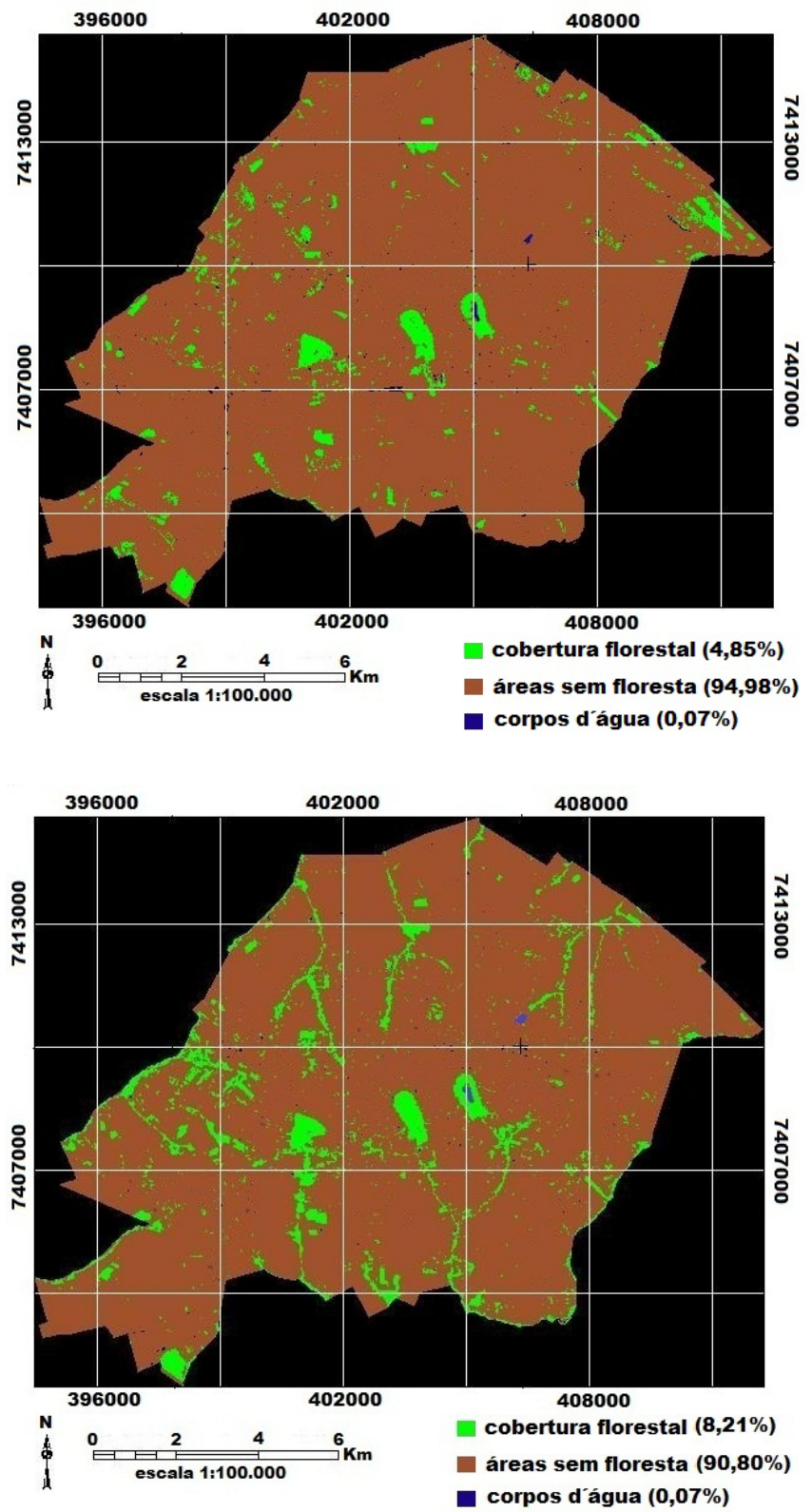
Figura 7. Classificação do setor norte da área rural de Maringá-PR das imagens Landsat 5, sensor TM, órbita 222, ponto 76, datas 06/08/1990 (acima) e 24/09/2008 (abaixo)

Figure 7. Classification of the northern rural sector of Maringá, PR from Landsat 5 images, TM sensor, orbit 222, point 76, dates 06/08/1990 (above) and 24/09/2008 (below)
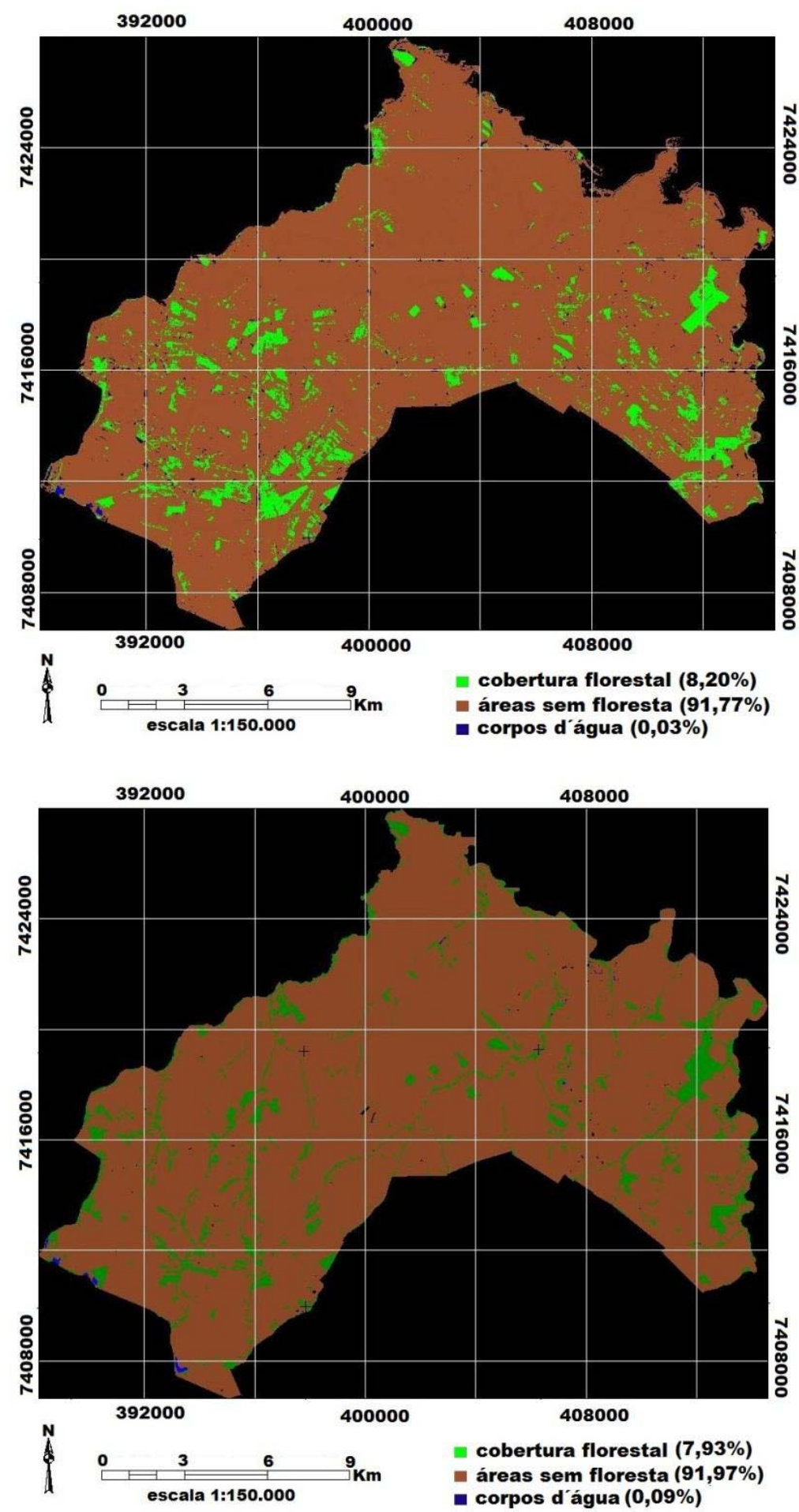

AVALIAÇÃO DA COBERTURA... 
Figura 8. Classificação do setor sul da área rural de Maringá-PR das imagens Landsat 5, sensor TM, órbita 222, ponto 76, datas 06/08/1990 (acima) e 24/09/2008 (abaixo)

Figure 8. Classification of the southern rural sector of Maringa, PR from Landsat 5 images, TM sensor, orbit 222, point 76, dates 06/08/1990 (above) and 24/09/2008 (below)
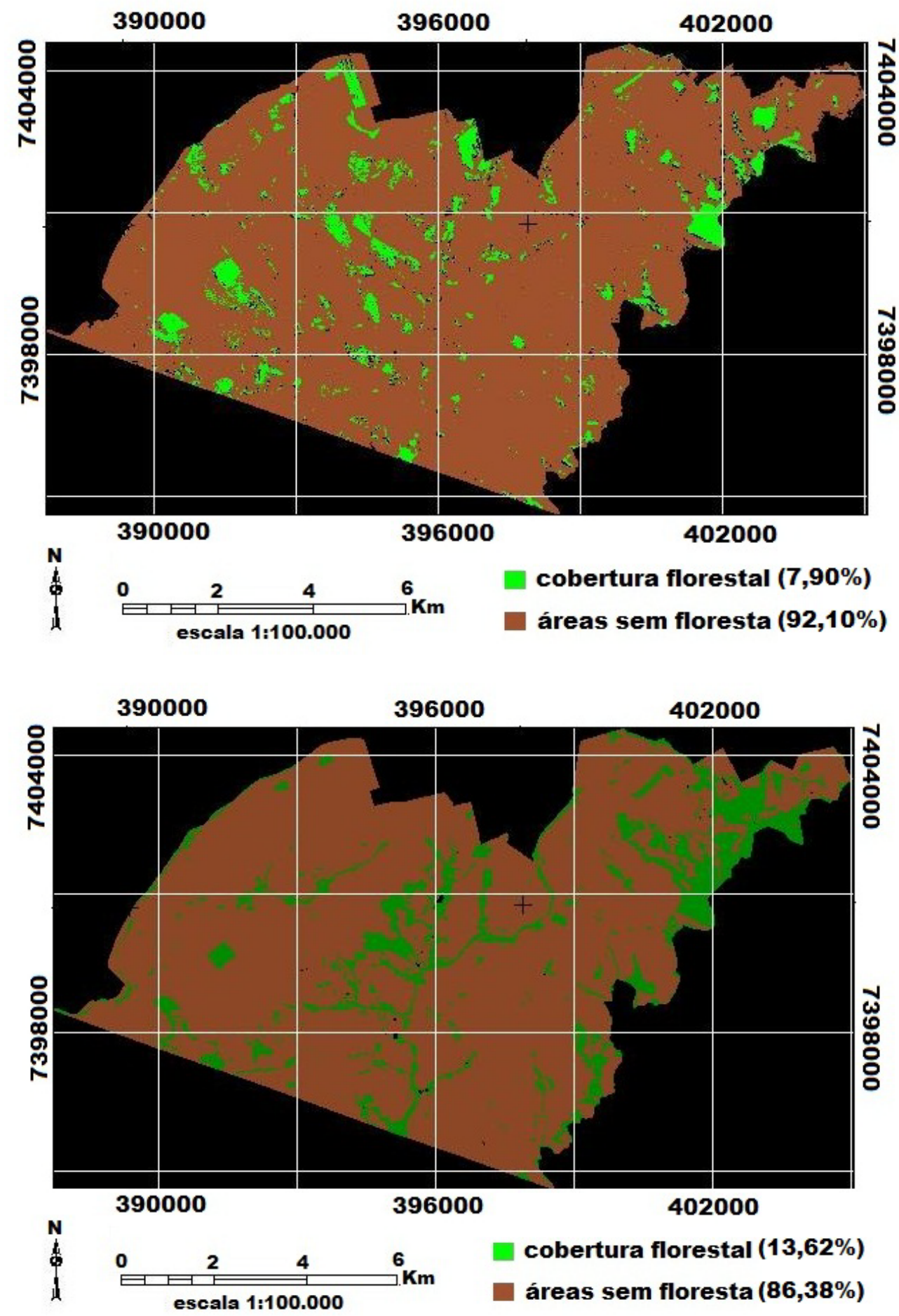

A paisagem do setor norte da área rural em 1990 tinha $8,2 \%$ de sua área com a presença de cobertura florestal.
Porém, as florestas ripárias dos principais cursos d’água se encontravam pouco evidentes. Sendo assim, a André Cesar Furlaneto Sampaio... 
paisagem apresentava precária conectividade entre remanescentes florestais, o que caracteriza o processo de fragmentação florestal. Em 2008 pôde-se verificar que no setor norte restaram apenas 7,9\% dos remanescentes ou plantios florestais, ou seja, estimou-se uma redução de 0,71 km2 de área de florestas, o que equivale a cerca de 0,2\% de toda área do município.

No setor sul da área rural verificou-se que de 1990 até 2008 houve um aumento da cobertura florestal de 7,9\% para 13,6\%, o que representa incremento de 4,99 km2 equivalente a cerca de $1,0 \%$ de toda a área do município. Observou-se que apesar de terem ocorridos desmatamentos entre 1990 até 2008, também ocorreu uma recuperação da cobertura florestal principalmente nas florestas ripárias, que em 1990 não se encontravam evidentes.

No Atlas da Mata Atlântica de 2008, onde foi calculada a área de remanescentes florestais deste bioma em todo Brasil, consta um resultado de 3\% de remanescentes florestais no município de Maringá (FUNDAÇÃO SOS MATA ATLÂNTICA; INPE, 2009). Os resultados da presente pesquisa mostram para o ano de 2008 uma cobertura florestal de todo município de Maringá de 9,0\%
(43,91 km2), acima do resultado apresentado pelo estudo anterior. Porém, é preciso ressaltar que foram utilizadas metodologias diferentes. Neste trabalho, considerou-se toda a cobertura florestal do município, contabilizando plantios comerciais e vegetação florestal arbórea em todos os estágios de sucessão. No estudo anterior, foram considerados apenas fragmentos de floresta nativa no estágio avançado da sucessão e com mais de cinco hectares de área.

Para a área rural no ano de 1990 a cobertura florestal totalizou 5,9\% da área do município, sendo que na área urbana a cobertura florestal representou cerca de 1,4\%. No ano de 2008, a cobertura florestal em área rural atingiu 6,7\% da área do município e para área urbana verificou-se cobertura florestal de 2,2\% (Tabela 1 ).

De 1990 até 2008, observou-se um acréscimo de cobertura florestal de 25,2\% no município de Maringá. Isso parece decorrer principalmente de um processo de ampliação da vegetação florestal ripária, especialmente na área urbana e na área rural sul. Na área rural norte houve uma pequena diminuição da cobertura florestal, mas também pode-se observar uma tendência de ampliação da vegetação ripária.

Tabela 1. Quantificação da cobertura florestal nos diferentes setores de Maringá-PR, baseada em imagens Landsat 5, sensor TM, órbita 222, ponto 76, nas respectivas datas 06/08/1990 e 24/09/2008

Table 1. Quantification of forest cover in different sectors of Maringá-PR, based in Landsat 5 images, TM sensor, orbit 222, point 76, on the respective dates 06/08/1990 and 24/09/2008

\begin{tabular}{|c|c|c|c|c|}
\hline $\begin{array}{c}\text { Imagem } \\
\text { Landsat } 5\end{array}$ & $\begin{array}{l}\text { Área Rural Norte } \\
\qquad\left(\mathrm{Km}^{2}\right)\end{array}$ & $\begin{array}{c}\text { Área Rural Sul } \\
\left(\mathbf{K m}^{2}\right)\end{array}$ & $\begin{array}{c}\text { Área Urbana } \\
\left(\mathbf{K m}^{2}\right)\end{array}$ & $\begin{array}{r}\text { Total } \\
\left(\mathbf{K m}^{2}\right)\end{array}$ \\
\hline 1990 & 21,59 & 6,9 & 6,59 & 35,08 \\
\hline 2008 & 20,87 & 11,89 & 11,15 & 43,91 \\
\hline
\end{tabular}

Houve desenvolvimento dos corredores ecológicos através da consolidação de florestas ripárias. Porém, esses se mostram estreitos e sujeitos a invasão de espécies exóticas invasoras. De acordo com Blum et al. (2008) o município de Maringá apresenta algumas espécies exóticas invasoras bastante agressivas como Leucena leucocephala, que pode comprometer seriamente a biodiversidade e o equilíbrio ambiental na região, principalmente nas matas ciliares do município. 


\section{CONCLUSÕES}

A cobertura florestal do município de Maringá foi ampliada desde 1990, especialmente nas margens dos rios. Isso se deve provavelmente às políticas e leis ambientais que começaram a ter melhor fiscalização e cobrança a partir da década de 90 , principalmente o Código Florestal (Lei 4.771/65), que exige a restauração das Áreas de Preservação Permanente.

O aumento de cobertura florestal identificado no presente estudo sugestiona uma melhora ambiental. No entanto, é importante frisar que parte da cobertura florestal quantificada abrange plantios com espécies exóticas ou até mesmo áreas contaminadas por espécies exóticas invasoras, já que o presente trabalho não avaliou a qualidade da cobertura florestal. Deste modo, não se pode afirmar o quanto de perda ou ganho de diversidade de espécies pode ter ocorrido com a referida cobertura florestal.

As imagens utilizadas possuem resolução mínima para esse tipo de análise, mas percebe-se que o mais adequado para resultados mais satisfatórios seria a utilização de imagens com melhor resolução.

\section{REFERÊNCIAS BIBLIOGRÁFICAS}

BARROS, Z. X.; TORNERO, M. T.; STIPP, N. A. F.; CARDOSO, L. G.; POLLO R. A. Estudo da Adequação do Uso do Solo, no Município de Maringá - PR, Utilizando-se de Geoprocessamento. Engenharia Agrícola, Jaboticabal - SP, v.24, n.2, p.436-444, 2004.

BIERREGAARD, R. O. \& LOVEJOY, T. E. Birds in Amazonian forest fragments: effects of insularization. In: CONGRESSO INTERNACIONAL DE ORNITOLOGIA, XIX, 1988, Ottawa. Anais... Ottawa: University of Ottawa, 1988. p. $1564-1579$

BLUM, C. T.; BORGO, M.; SAMPAIO, A. C. F. Espécies exóticas e invasoras na arborização de vias públicas de Maringá, Paraná. Revista da Sociedade Brasileira de Arborização Urbana, Piracicaba - SP, v.3 n.2, p.78-97, 2008.

CASTELLA, P. R.; R. M. BRITEZ. A floresta com araucária no Paraná: conservação e diagnóstico dos remanescentes florestais. Brasília: Ministério do Meio Ambiente, 2004. 236p.

CAVAlHEIRO, F. O Planejamento de espaços livres: o caos de São Paulo. In: CONGRESSO NACIONAL SOBRE ESSENCIAS NATIVAS, 1982, Campos do Jordão. Anais... São Paulo, 16(A-3): p. 1819-1830.

DEMATTÊ, M. E. S. P. Princípios de paisagismo. Jaboticabal: FUNEP, 1997. 104p.

DURIGAN, G.; FRANCO, G. A. D. C.; SAITO, M.; BAITELLO, J. B. Estrutura e diversidade de componente arbóreo da floresta na Estação Ecológica de Caetetus, Gália, SP. Revista Brasileira de Botânica, São Paulo - SP, v.23, n.2, p. 369-381, 2000.

FERNANDEZ, F. A. dos S. O poema imperfeito: crônicas de biologia, conservação da natureza, e seus heróis. Curitiba: Editora da Universidade Federal do Paraná, 2000. 
FERNANDEZ, F. A. S. Efeitos da fragmentação de ecossistemas: a situação das unidades de conservação. In: CONGRESSO BRASILEIRO DE UNIDADES DE CONSERVAÇÃO, 1., 1997, Curitiba. Anais... Curitiba: IAP/UNILIVRE/Rede Nacional Pró Unidade de Conservação, 1997, v.1, p.49-68.

IBGE - Instituto Brasileiro de Geografia e Estatística. IBGE Cidades@. 2010. Disponível em: <http://www.ibge.gov.br/cidadesat/default.php>. Acesso em 01 maio. 2011.

MAACK, R. Geografia física do Estado do Paraná. Curitiba: Max Roesner, 1968. 350 p.

MAACK, R. Mapa fitogeográfico do Estado do Paraná. Curitiba: IBPT, 1950. 1 mapa: color. Escala 1:750.000.

NUCCI, J. C. Qualidade ambiental e adensamento urbano: um estudo de ecologia e planejamento da paisagem aplicado ao distrito de Santa Cecília (MSP). São Paulo: USP, FFLCH, 2001. 236 p.

OLIVEIRA, C. H. Planejamento ambiental na cidade de São Carlos (SP) com ênfase nas áreas públicas e áreas verdes: diagnósticos e propostas. 1996. 181 f. Dissertação (Mestrado em Ecologia e Recursos Naturais) - Universidade Federal de São Carlos, Carlos, 1996.

PAIVA, R. G.; SANTOS, R. M.; GOMES, M. F.; GONÇALVES JUNIOR, F. A. A utilização de dados SRTM para análises ambientais: Elaboração de mapas de relevo do município de Maringá, Paraná, Brasil. In. ENCUENTRO DE GEÓGRAFOS DE AMÉRICA LATINA, 2009, Montevideo. Anais... Montevideo. Disponível em: <http://egal2009.easyplanners.info/area04/4054_garcia_paiva_raniere.pdf>. acesso em abril de 2011.

RODERJAN, C. V.; GALVÃO, F.; KUNIYOSHI, Y. S.; HATSCHBACH, G. G. As Unidades Fitogeográficas do Estado do Paraná. Ciência e Meio Ambiente - Fitogeografia do Sul da América. Santa Maria - RS, n. 24, p.75-92, 2002.

SAMPAIO, A. C. F.; DE ANGELIS, B. L. D. Inventário e análise da arborização de vias públicas de Maringá-PR. Revista da Sociedade Brasileira de Arborização Urbana. Piracicaba - SP, v.3 n.2, p.37-57, 2008.

SOCIEDADE BRASILEIRA DE ARBORIZAÇÃO URBANA - SBAU. Carta a Londrina e Ibiporã. Boletim Informativo, v.3 , n.5, p.3, 1996.

SOS MATA ATLÂNTICA \& INSTITUTO NACIONAL DE PESQUISAS ESPACIAIS (INPE). Atlas dos Remanescentes Florestais da Mata Atlântica - 2005-2008. Relatório Parcial. São Paulo, 2009. Disponível em: <http://mapas.sosma.org.br/site_media/download/atlas\%20mata\%20atlantica-relatorio2005-2008.pdf> Acesso em: 28 abr. 2011.

VELOSO, H. P.; GÓES-FILHO, L. Fitogeografia brasileira - classificação fisionômico-ecológica da vegetação neotropical. Boletim Técnico do Projeto RADAMBRASIL, Série Vegetação, v.1, n.1, 1982.

WILLIS, E. O. The composition ofavian communities in remanescent woodlots in southern Brazil. Papeis Avulsos de Zoologia, São Paulo, v.33, n.1, p.1-25, 1979. 